\title{
Genre Analysis of American Presidential Inaugural Speech*
}

\author{
Fang Liu \\ Changchun University of Science and Technology, Changchun, China \\ Email: 2005xiaoji@163.com
}

\begin{abstract}
English public speaking is an important social-cultural phenomenon of the west; as a specific form of discourse sharing the characteristics of both oral and written discourse. American Presidential Inaugural Address (APIA) has always been arousing scholars' great concern in the field of applied linguistics. It is delivered to the people at home and abroad when the newly elected presidents take office to make his government policy known to the public and persuade the public to accept and support his policy with worldwide influence and long-lasting significance. However, most studies on APS are mainly made from the perspective of translation, stylistics, rhetoric, and so on. Seldom effort is made within genre analysis which focuses both on the linguistic realization of a text and the communicative functions the text serves. With the moves as the possible generic structure for this particular genre, the communicative purposes of the genre are revealed.
\end{abstract}

Index Terms-American presidential inaugural speech, genre analysis, move, strategy

\section{INTRODUCTION}

The term "genre" is derived from the Latin word for "kind" or "class". It traditionally serves to indicate different kinds of literary and artistic works. In recent years, language educators and linguists have extended it to identify classes of language use and communication in all areas of life. Since 1970s, the focus in stylistics, text linguistics and syntactical features or formats of discourse has been transformed into a deeper and multi-layered explanation of the macro-structures and communicative functions of discourse, and thus genre analysis emerges and becomes an important branch of discourse analysis. There are two major schools in the field of linguistics concerning the concept "genre", the Swalesian School with the representatives of John M. Swales and Vijak K. Bhatia, and the Australian School with the representative of Jim R. Martin.

English political speaking, as a social-cultural product in the west, represents the western way of thinking and speaking. American Presidential Inaugural Addresses (APIAs) is commonly recognized as the representative of English political speaking. It is assumed that the research of APIAs from the perspective of genre analysis can promote the understanding of how writers or speakers select strategies to achieve their communicative purpose within the constraints imposed by the genre to which discourse belongs. This study aims to reveal how to be a good English political speaker and how to be an effective communicator in English.

\section{GenRe ANALYSIS}

\section{A. Genre}

Etymologically, the term "genre" originates from the Latin word "genus" and the earliest attention to it can be dated back to the ancient Greek and Roman period. In the past, the concept of "genre" was always confined to the field of literature, which was mainly divided into three types: lyric, epic, and drama. However, the extension to "genre" has expanded dramatically since its introduction into the field of applied linguistics in the 1970's. Such types of literature as novel, essay, biography and non-fiction are classified into the category of genre.

John M. Swales (1990) describes genre as a recognizable communicative event characterized by a set of communicative purposes identified and mutually understood by the members of the professional or academic community in which it regularly occurs. Most often it is highly structured and conventionalized with constraints on allowable contributions in terms of their intent, positioning, form and functional value. These constraints, however, are often exploited by the expert members of the discourse community to achieve private intentions with the framework of socially recognized purposes.

Bhatia (1993) expands Swales' term by bringing in the psychological, particularly cognitive, level of genre construction. Bhatia argues that although there are a number of other factors, like content, form, intended audience, medium or channel, which influence the nature and construction of a genre, it is primarily characterized by the communicative purpose that it is intended to fulfill. The shared set of communicative purposes shapes the genre and

\footnotetext{
* Note: This paper is sponsored by JLPOPSS with the code of 2010B29
} 
gives it an internal structure. Any major change in the communicative purposes is likely to give a different genre; however, minor changes or modifications help distinguish sub-genres. Bhatia finds that specialists of any professional or academic community are generally credited with the knowledge of not only the communicative goals of their community but also the structure of the genres in which they regularly participate as part of their daily work.

\section{B. Genre Analysis}

As mentioned above, the concept of "genre" is introduced into the field of applied linguistics in the 1970's. But the status of genre analysis is formally established in the 1980's when some applied linguists shift their attention from the surface description of language to the social and cultural explanation in the linguistic community. Genre analysis offers an analytic method that allows observation to be made on the repeated communicative functions found in genres and the linguistic exponents of these functions. As an admittedly new development of discourse analysis, genre analysis establishes itself after going through four stages, that is, register analysis, grammatical-rhetorical analysis, interactional analysis and genre analysis. As far as grammatical-rhetorical analysis is concerned, Trimble is an outstanding contributor. He shows his concern for non-literary texts and pays more attention to the study of general grammatical features of tense and article choices in scientific writings. As for interactional analysis, it focuses on the study of the social and linguistic meanings created during interaction and it evolves into "applied discourse analysis", "speech function analysis" etc. eventually. It is generally considered that genre analysis is the development of the three analytic approaches mentioned above. Compared with the other three analytic approaches, genre analysis emphasizes the psychological process of the text construction. Through the presentation and analysis of the regular organization together with other linguistic features of a text, genre analysis offers a deeper explanation of relationship between the form and the function. There are some important concepts within genre analysis.

1. Move

A move can be thought of as part of a text, written or spoken, which achieves a particular purpose within the text. As Swales claims, is the basic unit for analysis of the target text. Mirador (2000) gave a conceptual formulated definition based on the genre analysis of written feedback from tutors to students as follows:

Move is the logic maneuver adopted by the communicators in written or spoken discourse. Such maneuver is evident in the unified functional meaning of a sentence or group of sentences in a written or spoken text. The sentence or group of sentences has a single unifying purpose in relation to the context in which it occurs.

Hence, the move contributes, in some way, to fulfilling the overall purpose of the genre.

2. Strategy \& Step

In the process of analyzing a genre, "strategy" and "step" are another two terms most frequently used besides "move". According to Bhatia, "strategy" refers to the way the writer or speaker adopted to execute or concrete the move. He also says "In order to realize a particular communicative intention at the level of a move, an individual writer may use different rhetorical strategies". "Step" used by Swales in his CARS model has nearly the same function. The author argues that the two terms are units subordinate to "move", and that the two terms have nearly the same connotations. With the recent academic development, the term "strategy" is most frequently used by researchers and scholars both at home and abroad.

\section{APS AS AN IMPORTANT PART OF ENGLISH POLITICAL SPEAKING}

English political speaking (EPS) is one that the speaker, on behalf of a certain class, society, or party, usually makes in English to an audience on some important matters and relationships home and abroad.

The political speaking generally has three purposes: to convince people to take action as the speaker expects, to change radically their attitudes or beliefs or to weaken their current attitudes or beliefs. These are also the basic functions of the political public speaking.

\section{A. Characteristics of English Political Speaking}

The basic characteristic of EPS is of strong political tendency with rigid logic and arousing force. As an effective political speech, it must contain at least the following characteristics: about ethics, aesthetics, sociology, psychology, logic, literature and linguistics. In more details, it means that the speech language should fulfill at least these functions: to present the sound and correct political opinion, to attract the audience and make them into serious thinking, to move and persuade them to accept the speaker's viewpoints, to encourage the audience to do what the speaker wants them to do.

Therefore, the requirements for English political speaking are much more strict and solemn. Just as a famous orator comments: The public speech has a structure of paper, truth of news item, language of a fiction, passion in a poem, material of a prose, and the humor of a comic dialogue.

However, what the paper wants to focus on is the characteristics of a political speaking, which can be properly achieved by means of some stylistic features. First, the political viewpoint is quite firm and clear. In a speech, the speaker must tell his audience what he wants to express today and what his political opinion is about this matter. Second, the political speaking must be endowed with overwhelming power of logic that is eloquent and with no chink in the armor. And third, the political speaking should burst forth the intense inspiring force. 


\section{B. American Presidential Inaugural Address (APIA) as Typical Example of APS}

The inaugural address is the speech delivered by the president-elect on the inauguration day. In the speech, for the first time, the newly elected president will officially announce that he will take up the responsibility as the highest executive of the country in the next four years. Inaugurals mark the end of the election campaign and at the same time the beginning of a new administration. Although the inaugural address is not required by the constitution, it is made every four years by all the presidents before they take the office. It has already become a tradition set by the first president--George Washington. As a rule, the new administrator's philosophy of politics and the outline of his policy will be pronounced in his inaugural address. The inauguration is held as a celebration witnessed by many audiences. Inaugurals are of great significance because of what they reveal about the fundamental political values, particular political principles, and enactment of a presidential persona. Their political meanings thus become clear. Inaugural addresses attempt to persuade the citizens of the nation that the newly elected president is fit for the political role and that he is entitled to achieve his programmatic objectives. The addresses, then, cast much light on the legitimacy of political power and the worldviews of Presidents. Their political intention is to call for support and loyalty to a political regime from both other power-holders in the political system and the public at large during their administration. But the inaugural addresses by nature are epideictic prescribed by the inauguration itself.

According to Campbell and Jamieson, the inauguration is "a ritual of transition in which the covenant between the citizenry and their leaders is renewed". It is a series of symbolic acts undertaken since ancient ages by virtually all cultures in moments of change in leadership. Inauguration links present and even future closely with the past, which basically is believed to be an individual's and a culture's source of orientation. This cultural transition is usually celebrated ceremonially by assembled members of societies. Through the inauguration the hope for future prosperity is articulated, which is founded upon the qualities of the leader being given office and traditional values being reasserted. Thus the inauguration ceremony may be defined as a ritual whereby an institutional role is called up and embodied by the person filling it. In this ceremony, a leader assumes and expresses power.

\section{Genre Analysis of American Presidential InAUgural AdDREsses}

Based on the framework constructed in the preceding chapters, this chapter focuses on the genre analysis of APIAs. To locate the features of presidential inaugurals in structure, this paper takes all the inaugural addresses into the corpus. It includes altogether thirty-five addresses ranging from the first speech of President Washington to the latest of President Obama. Each presidential inaugural address has been carefully studied by the author. Despite the variation in tones, themes and forms, the regularities in the internal structure have been sought and analyzed.

\section{A. Identification}

As the communicative purpose is the criterion to distinguish a genre, the communicative intention can be considered as the defining feature for moves. Whenever a linguistic unit indicates a communicative intention subservient to the general communicative purpose of the discourse a move can be identified. The combination of these communicative intentions makes the communicative purpose of the particular genre.

Since submoves are non-discriminative, a linguistic unit that indicates the same communicative intention, or only part of the whole, or a unit that is just a different strategy to accomplish the same intention, can only be identified as submoves or steps.

Otherwise, it can be a new move. In the case of move-structure of article introduction summarized by Swales, the writer may decide to establish the research field either by:

(a) asserting centrality of the topic or

(b) stating current knowledge or

(c) ascribing key

depending upon the constraints like the nature of the topic/field, the background knowledge of the intended readership, reader-writer relationship etc. These strategies are essentially non-discriminative type and belong to submoves.

To identify moves and submoves, linguistic clues such as explicit lexical items, phrases, grammatical specifiers of content relations, discourse conjuncts should also be resorted to.

\section{B. Move-structure Analysis}

\section{Move I - Salutation}

Except for thirteen speeches, all of the presidential inaugural addresses begin with a salutation. As other speeches, the salutation of inaugurals formally announces the commencement of this event and routinely direct the attention of the audience to the content of the address.

The salutation of presidential inaugurals normally takes two forms: addressing the audience as a whole and respectively. In the former case, salutations appear like: "Fellow-citizens", "My Fellow-citizens", "My countrymen", "Fellow-citizens of the United States", "Fellow-countrymen" etc. Almost all presidents of the early times, through 19 century to the early 20 century, abide by this custom. In such salutations all the American people are addressed equally and wholly. While in the latter case, many titles are mentioned. Some examples are listed as follows: 
Chief Justice Rehnquist Carter, President Clinton, distinguished guests and my fellow citizens: (Bush, 2001).

Mr. Vice President, Mr. Speaker, Mr. Chief Justice, Senator Cook, Mrs. Eisenhower, and my fellow citizens of this great and good country we share together:(Nixon, 1973).

2. Move II - Announcing entering upon office

The new presidents usually make announcement at the very beginning of their speech. But there are some who declare that they accept the office near the close. President Roosevelt claimed to take office after he had put forth his political principle. He said:

In taking again the oath of office as President of the United States, I assume the solemn obligation of leading the American people forward along the road over which they have chosen to advance.

This is a typical announcement of taking office, especially by presidents of early times, in which the presidents emphasized that they were "called upon by American people" or "the country" to execute the responsibility and they were "elected by people".

3. Move III - Articulating sentiments on the occasion

On the inaugural ceremony most of the new presidents will utter their sentiments on the occasion when they formally assume the responsibility as the chief executive of the country. In most cases, the new president will express his acknowledgements to American people for their trust and also to the predecessors for what they have done to this country. Clinton voiced his gratitude in this way:

On behalf of our nation, I salute my predecessor, President Bush, for his half-century of service to America. (Clinton, 1993)

Together with thanks, the magnitude of responsibility as president is also verbalized. President Taylor claimed:

When I reflect that the acceptance of the office which their partiality has bestowed imposed the discharge of the most arduous duties and involves the weightier obligations, I am conscious that the position which I have been called to fill, though sufficient to satisfy the loftiest ambition, is surrounded by fearful responsibilities. (Taylor, 1849)

4. Move IV — Making pledges

This move intends to fulfill the expectations of audience for promise. The new president carries out this speech act to help the pubic with confidence in the new leader and his government. The following is Jackson's pledges:

It shall be displayed to the extent of my humble abilities in continued efforts so as to administrate the Government as to preserve their liberty and promote their happiness. (Jackson, 1833)

5. Move $\mathrm{V}$ - Arousing patriotism in citizens

The function of this move is to bear the audience with love for the country and confidence in the future, with which the new president successfully unites all the Americans as a whole. A good way is to review the American history. An instance of this is given below:

It is now three days more than a hundred years since the adoption of the first written constitution of the United States--the Articles of Confederation and Perpetual Union. The new Republic was then beset with danger on every hand. It had not conquered a place in the family of nations. The decisive battle of the war for independence, whose centennial anniversary will soon be gratefully celebrated at Yorktown, had against the settled opinions of mankind; for the world did not then believe that the supreme authority of government could be safely entrusted to the guardianship of the people themselves.(Garfield, 1881)

6. Move VI - Announcing political principles to guide the new administration

This move is indispensable for setting forth political principles and that is also the main expectations of the audience from the speech.

Generally, the political principles that will control the government include two parts: those basic principles on which stand the American political institutions and the main policies that will shape the coming administration. The basic principles that all presidents swear to follow comprise American Constitution, union, freedom and democracy as Garfield had stated:

Under this constitution the boundaries of freedom have been enlarged, the foundations of order and peace have been strengthened, and the growth of our people in all the better elements of national life has indicated the wisdom of the founders and given new hope to their descendents. Under this Constitution our people long ago made themselves safe against danger from without and secured for their mariners and flag equality of rights on all the seas. Under this Constitution twenty-five states have been added to the Union, with constitution and laws, framed and enforced by their own citizens, to secure the manifold blessings of local self-government. (Garfield, 1881)

The second strategy adopted is to point out problems. In this method, the governing principles are put forth as the solutions to the problems. For an instance, Roosevelt put forward policies to solve the problems during the Depression:

Our greatest primary task is to put people to work...

Hand in hand with this we must frankly recognize the overbalance of population in our industrial centers and, by engaging on a national scale in a redistribution and endeavor to provide a better use of the land for those best fitted for the land....

Finally, in our progress toward a resumption of work we require two safeguards against a return of the evils of the old order; there must be a strict supervision of all banking and credits and investments; there must be...(Roosevelt, 1933) 
7. Move VII — Appealing to the audience

The audience can never be ignored. There is always a general appeal for aids or assistance or some specific appeal for sacrifice and dedication as displayed in the following:

Convinced that I owe my election to the inherent love for the constitution and the union which still animates the hearts of the American people, let me earnestly ask their powerful support in sustaining all just measures calculated to perpetrate these.. (Buchanan, 1857)

And so, my fellow Americans, ask not what your country can do for you--ask what you can do for your country.

(Kennedy, 1961)

8. Move VIII — Resorting to religious power

Every president will refer to God many times in his inaugural address as God is the common religious belief fornearly all Americans. The function of this move is to unite the American people. Generally presidents supplicate the help of God by two means: invoking God for guidance and seeking divine blessings. Examples are listed to explicate the two cases:

In assuming responsibilities so vast, I fervently invoke the aid of that Almighty Ruler of the Universe in whose hands are the destinies of nations and of men to guard this Heaven--favored land against the mischief which without his guidance might arise from an unwise public policy. (Polk, 1845)

God bless you all, and God bless America. (Bush, 2001)

\section{Conclusions}

Genre analysis not only reveals the available form-function relationship of a text or discourse but also contributes significantly to language learners' understanding. Through examining the communicative purposes, rhetoric situations, functions and generic traditions of inaugural address, presidential speech can be regarded as a genre. Since any genre will have its own particular cognitive structure to follow, the schematic structure of presidential speech is investigated into. After summarizing the well-known inaugural speeches, eight moves as the possible generic structure for this particular genre are explained respectively. These eight moves are rehearsed, analyzed and exemplified. Each communicative intention of these moves is in obedient to the overall communicative purposes of the genre. The various devices to accomplish these moves are enumerated. What's more, the linguistic characteristics that usually signal the moves are revealed. To sum up, through the attempt, we can see that genre analysis is a practical means of studying spoken and written discourse for applied ends.

\section{REFERENCES}

[1] Bhatia, V. K. (1991). A Genre-Based Approach to ESP Material Development. World Englishes 10 (2): 1-14.

[2] Bhatia, V. K. (1993). Analyzing genre: language use in professional settings. New York: Longman Publishing.

[3] Flowerdew, L. (2000). Using a genre-based framework to teach organizational structure in academic writing. ELT Journal, 47 (4): 369-378.

[4] Mirador, J. F. (2000). A move analysis of written feedback in higher education. RELC Journal, 31 (1): 45-60.

[5] Sinclair, J. \& R. M. Coulthard. (1975). Towards an analysis of discourse. Oxford: Oxford University Press.

[6] Swales, J.M. (1990). Genre analysis: English in academic and research settings. Cambridge: Cambridge University Press.

[7] Trimble, L. (1985). English for science and technology: a discourse approach. Cambridge: Cambridge University Press.

[8] Wang Junling. (2010). A Critical Discourse Analysis of Barack Obama's Speeches, Journal of Language Teaching and Research 1 (3): 254-261.

[9] Widdowson, H. G (1973). Principle \& practice in applied linguistics. New York: Oxford University Press.

Fang Liu was born in Jilin Province of China, on October 23rd, 1976. She has obtained Master's Degree of Arts in Foreign Linguistics and Applied Linguistics from Jilin University, Changchun, Jilin Province, China, in 2006.

As a LECTURER, she teaches Applied Linguistics at School of Foreign Languages, Changchun University of Science and Technology. Her previous research interests are Applied Linguistics and Intercultural Communication. One book (as an editor) and two published articles are as follows: [1] The Breakthrough of Three English Skills (Changchun, Jilin Province: Jilin University Press, 2009); [2] Social Constructivism and Foreign Language Teaching (Changchun, Jilin Province: Chinese Campus Literature, 2009); [3] Task-based Language Teaching Method and College Foreign Language Teaching (Changchun, Jilin Province: 21 Century Foreign Language Teaching and Research, 2008). At present she mainly focuses on Intercultural Pragmatics \& Cognitive Linguistics. 